\title{
Um modelo de processo para o anteprojeto de sistemas de informação em organizações públicas: Uma aplicação na Prefeitura Municipal de Salvador
}

\author{
Teófilo T. Branco Jr., Paulo Caetano da Silva
}

Programa de Pós-graduação, Mestrado em Sistemas e Computação - Universidade Salvador (UNIFACS)

\author{
41.820-460 - Salvador - BA - Brazil \\ teofilotb@hotmail.com, paulo.caetano@pro.unifacs.br
}

\begin{abstract}
The identification of business needs and the organization's environment is important so that information systems meet the desired purposes. In public organizations, typically, the definition and hiring in the development of information systems do not happen in a systematic way. With the aim of improving the efficiency of systems development in the context of public organizations, this article presents a model procedure for the identification of the requirements in the draft phase of information systems development. The implementation of this process happened in the Mayor's Office of the Municipality of Salvador, which provided improvements in the development of the systems which will be discussed in this article.
\end{abstract}

Resumo. A identificação das necessidades do negócio e o do ambiente da organização é importante para que os sistemas de informação atendam aos propósitos desejados. Nas organizações públicas, normalmente, a definição e contratação de desenvolvimentos de sistemas de informação não ocorre de maneira sistematizada. Com o objetivo de melhorar a eficiência de desenvolvimento de sistemas no contexto das organizações públicas, este artigo apresenta um modelo de processo para a identificação dos requisitos na fase do anteprojeto dos sistemas de informação. A implementação deste processo ocorreu na Prefeitura Municipal de Salvador proporcionando melhorias no desenvolvimento dos sistemas que serão discutidas neste artigo.

\section{Introdução}

O uso de sistemas de informação na área pública é um dos meios para resolver problemas relacionados aos controles exigidos aos órgãos públicos para o atendimento ao cidadão de forma eficiente. O retorno do investimento em sistemas de informação na esfera pública traduz-se em uma melhor administração do Estado em benefício do cidadão. Por isso, os investimentos neste ambiente devem considerar prioritariamente os benefícios ao atendimento das necessidades e interesses do cidadão. (Muniz, 2006).

Para La Costa \& Zoucas (2002), nem sempre os que demandam sistemas têm uma percepção de quais são os desafios e problemas envolvidos no desenvolvimento de projetos de sistemas de informação. É comum que gestores não saibam como as tecnologias de informação podem ser usadas para atingir os objetivos do negócio. O uso da tecnologia da informação sem alinhamento com os objetivos estratégicos e táticos da 
instituição pode ser danoso à estrutura pública, despendendo recursos para uma finalidade que não seja prioritária. Outro problema reside no fato dos sistemas de informação (SI) desenvolvidos, normalmente, trazerem poucos benefícios para o atendimento ao público. Iniciativas desse tipo consomem recursos públicos desnecessariamente, que quase sempre levam a obsolescência precoce do sistema, resultando em prejuízos financeiros aos cofres públicos. (Muniz, 2006).

É proposto neste trabalho um modelo de processo para o anteprojeto de sistemas de informação que seja capaz de identificar aspectos importantes, como o reconhecimento do ambiente organizacional e a relação entre as funcionalidades e os objetivos estratégicos, essenciais para que os SI produzam bons resultados e sejam úteis. Este modelo tem por finalidade estruturar e explicitar requisitos que justifiquem a seleção de projetos de SI para implementação.

Entende-se como fase de anteprojeto, a fase anterior ao processo de iniciação do projeto (PMBOK, 2008), na qual são realizadas prospecções relativas ao ambiente organizacional e realizados estudos de viabilidade com o objetivo de subsidiar a decisão dos gestores sobre a sua consecução.

Este artigo está organizado da seguinte forma: A Seção 2 discute o referencial teórico utilizado no trabalho, Na Seção 3, é apresentada a metodologia de pesquisa que foi aplicada, seguindo-se dos trabalhos correlatos apresentados na Seção 4. Na Seção 5, é apresentado o modelo proposto. Na Seção 6 é descrita a aplicação do modelo, seguindo-se dos resultados observados e, finalmente, na Seção 7, são apresentadas as conclusões e os trabalhos futuros recomendados para este trabalho.

\section{Referencial teórico}

Foram revistos conceitos referentes a engenharia de software e técnicas atualmente empregadas na engenharia de requisitos, os quais constituíram o embasamento teórico do modelo de processo apresentado neste trabalho.

O RUP é um processo de desenvolvimento de software utilizado por organizações e na academia (Kruchten, 2003). O RUP define o workflow "Modelagem de Negócio", cujo objetivo é modelar os processos de negócio, que descreve como desenvolver uma visão sobre a organização para definir seus processos, regras e responsabilidades, em um Modelo de Casos de Uso de Negócio e em um Modelo de Objetos de Negócio. Entretanto, segundo observado por Chichinelli \& Cazarini (2001), o RUP tem uma expressividade limitada na modelagem de negócios, não permitindo modelar motivações, intenções e razões associadas aos processos organizacionais.

O MPS-BR (SOFTEX,2011) baseia-se nos conceitos de maturidade e capacidade de processo para a avaliação e melhoria da qualidade e produtividade de produtos de software e serviços correlatos. Este guia descreve o processo de aquisição de software e serviços relacionados ao desenvolvimento, implantação, operação e evolução do software. O processo de aquisição tem como propósito obter um produto ou serviço que satisfaça a necessidade expressa pelo cliente. Esse processo possui uma fase denominada: preparação da aquisição, que tem o propósito de estabelecer as necessidades e os objetivos da aquisição e comunicá-los aos fornecedores. Entretanto, o 
guia de aquisição do MPS-BR considera que a decisão de aquisição já está tomada e não trata do processo decisório em si, deixando lacunas em relação a esse processo.

O PMBOK (PMI, 2008), define uma série de processos reconhecidos como boas práticas em gerenciamento de projetos e aplicáveis à maioria dos projetos. Os processos de gerenciamento de aquisições do projeto incluem as seguintes atividades: planejar compras e aquisições; determinação do que comprar ou adquirir e de quando e como fazer isso. Entretanto, o PMBOK trata estas questões somente após a implementação do projeto já ter sido decidida, não tratando do processo relacionado à preparação do processo anterior, ou seja, da escolha e da decisão. Como o processo de aquisição abordado pelo PMBOK inicia-se após a decisão de adquirir, nota-se uma lacuna que se pretende preencher com o escopo deste trabalho, situando-o em uma fase preliminar, denominada neste trabalho como fase do anteprojeto.

\section{Metodologia de pesquisa}

Uma revisão sistemática da literatura foi conduzida no intuito de encontrar e analisar trabalhos relevantes e reconhecidos na área acadêmica que pudessem responder as seguintes questões de pesquisa: (i) como os sistemas podem ser considerados inadequados; (ii) quais são as consequências de sistemas inadequados; e (iii) o que ocasiona sistemas de informação inadequados. O resultado da revisão sistemática apontou como principais causas para as questões de pesquisa levantadas: a falta de planejamento nos processos de tomada de decisão de SI; a falta de alinhamento estratégico; e a carência no levantamento dos requisitos não funcionais no reconhecimento do ambiente organizacional.

A metodologia escolhida para pesquisa foi a Pesquisa Ação, "Action Research", derivada do método estruturalista (Marconi \& Lakatos, 2007). A partir de induções, propõe-se uma abordagem reunindo um conjunto de práticas, constituindo a base do processo experimental da qual participam os próprios atores envolvidos no contexto de pesquisa de forma participativa colaborativa. Com base nesta metodologia, definiu-se o método "Estruturalista" com abordagem de natureza "Qualitativa" para critério de avaliação da pesquisa.

\section{Trabalhos correlatos}

La Costa \& Zoucas (2012) considera que o processo de engenharia de software no setor público é uma tarefa complexa, em razão do desenvolvimento de SI comumente ser de interesse de mais de um setor da sociedade e envolver mais de uma área administrativa. Segundo os autores, a equipe de desenvolvimento deve se dedicar a compreensão do problema, mesmo com acréscimo de tempo para esta fase. Para embasar suas afirmativas, é apresentado um relato de experiências no desenvolvimento de softwares para instituições públicas de diversos países. Entretanto, os autores informam que a pesquisa teve somente o objetivo de identificar os estudos de casos de desenvolvimento de software no setor público através dos relatos das lições aprendidas.

Tamaki (2007) apresenta uma estratégia para possibilitar a extensão do RUP buscando identificar possíveis lacunas perante os processos recomendados pelo PMBOK (PMBOK, 2008). A estratégia utilizada foi a definição de um método de 
melhoria de processos do RUP, alterando as suas fases em um modelo de sua autoria. Porém, a proposta pode se tornar prejudicada pela sua complexidade.

Ameller \& Ayala (2012) afirmam que lidar com requisitos não-funcionais tem sido um desafio para os engenheiros de software. Neste trabalho, eles se limitam a apresentar os resultados de uma revisão sistemática, no qual sugerem haver falta de conhecimento sobre como gerenciar requisitos não funcionais, o que é associado à hipótese deste fato estar concernente com a menor importância destes requisitos em relação aos requisitos funcionais.

Moreira \& Silva (2013), apresentam uma proposta de gestão de processos de negócios através do BPM e implantação de governança de TI através de boas práticas de governança em tecnologia da informação aceitas pelo mercado e academia, possibilitando assim criar um ambiente corporativo e de TI gerenciável. A proposta se limita a um modelo de governança aplicável a qualquer organização sem especificar a realidade de TI no serviço público particularmente.

Foram avaliadas metodologias de desenvolvimento de sistemas utilizadas em organizações públicas brasileiras: Banco do Estado do Espírito Santo (Banestes, 2010); Supremo Tribunal Federal (STF, 2009); Ministério da Educação - Instituto Nacional de Estudos e Pesquisas Educacionais Anísio Teixeira (MEC-INEP, 2010); Tribunal Regional do Trabalho (TRT, 2010) e o Centro de Tecnologia de Informação e Comunicação do Estado do Rio de Janeiro (PRODERJ, 2010). Puderam ser feitas as seguintes observações: (i) em nenhuma delas há o reconhecimento dos recursos de TI pré-existentes, pressupondo que a infraestrutura será garantida, seja qual for necessidade do sistema demandado; (ii) em todas elas os estudos de viabilidade mencionam somente estimativas de custos e de tempo; (iii) em três organizações é prevista a contratação de uma única empresa para o atendimento de todas as demandas de SI. Duas delegam a totalidade dos estudos da demanda e do software à empresa contratada, bem como o levantamento dos custos e a estimativa de tempo para seu atendimento; (iv) a verificação dos objetivos organizacionais do demandante, na verificação da aderência da demanda aos objetivos estratégicos é sugerida em três das organizações estudadas.

\section{Um Modelo de Processo para o Anteprojeto de SI}

Esta seção apresenta o modelo de processo para a elicitação de requisitos que servirão para a tomada de decisão sobre a implementação de sistemas de informação, que corresponde ao acréscimo de uma etapa denominada de Anteprojeto nas metodologias para desenvolvimento de sistemas (MDS), conforme ilustrado na Figura 1.

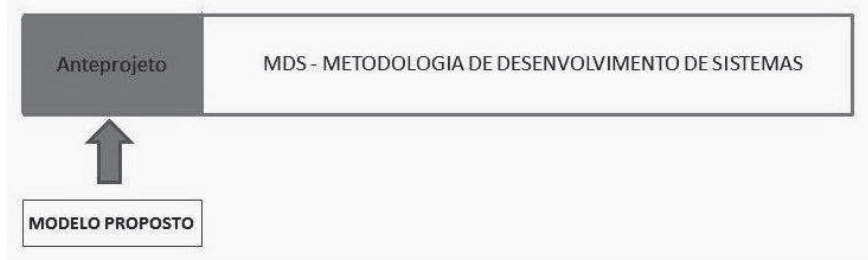

Figura 1. Inclusão do Modelo proposto na MDS

O modelo de processo proposto tem por objetivo subsidiar a fase preliminar da concepção do sistema, fornecendo uma documentação referencial para a consecução das 
fases posteriores no processo de desenvolvimento do software. Ele é composto de seis etapas denominadas: (i) identificação da necessidade ou oportunidades de demanda de SI; (ii) compreensão do contexto e do domínio da aplicação; (iii) coleta de requisitos básicos ao entendimento do SI; (iv) estudo de viabilidade de projeto de SI; (v) elaboração de proposta de SI e; (vi) elaboração da documentação legal para processo de aquisição de SI. As etapas estão ilustradas na Figura 2.

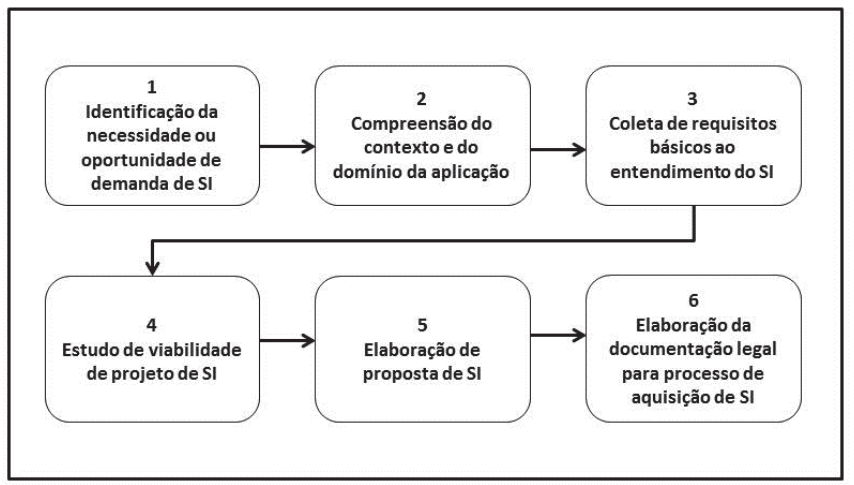

Figura 2. Etapas do modelo

A seguir são descritas as seis etapas propostas para o processo, são esclarecidos seus objetivos e as principais atividades desenvolvidas em cada uma delas:

\subsection{Identificação da necessidade ou oportunidade de demanda de SI}

Um grande fator motivador de sistemas de informação é a verificação de oportunidades e necessidades decorrente de análises dos processos de negócio. Outro fator gerador de demanda por sistemas de informação ocorre na execução das rotinas de trabalho, nas quais a percepção de dificuldades para sua execução podem inspirar os usuários a idealizarem sistemas para melhorar o desempenho de suas áreas. Esta etapa tem como objetivo detectar a necessidade e/ou oportunidade de sistema de informação para apoio ou otimização do negócio do órgão demandante. Ela representa o marco inicial para o processo de solicitação de desenvolvimento de SI, através da formalização de sua necessidade, cujas atividades são descritas na Tabela 1.

Tabela 1. Atividades previstas na primeira etapa

\begin{tabular}{|l|l|c|}
\hline \multicolumn{1}{|c|}{ Atividade } & \multicolumn{1}{c|}{ Descrição } & Responsável \\
\hline $\begin{array}{l}\text { Identificação da demanda } \\
\text { de SI }\end{array}$ & $\begin{array}{l}\text { Identificada uma demanda de SI para atendimento } \\
\text { a área demandante. }\end{array}$ & \\
\cline { 1 - 2 } $\begin{array}{l}\text { Avaliação da demanda pela } \\
\text { administração do órgão } \\
\text { demandante }\end{array}$ & $\begin{array}{l}\text { A demanda de SI verificada é submetida ao gestor } \\
\text { do órgão demandante para sua análise e } \\
\text { aprovação. }\end{array}$ & \multirow{2}{*}{ Órgão } \\
Abertura formal de & É elaborado o documento de solicitação de & \\
solicitação de demanda SI & Demanda de SI & \\
\cline { 1 - 2 } $\begin{array}{l}\text { Encaminhamento da } \\
\text { demanda ao órgão de TI }\end{array}$ & $\begin{array}{l}\text { O documento de solicitação da demanda de SI é } \\
\text { enviado ao órgão de TI para análise. }\end{array}$ & \\
\hline
\end{tabular}

\subsection{Compreensão do contexto e do domínio da aplicação}

Esta etapa tem como finalidade identificar a missão do órgão demandante, seus objetivos estratégicos e sua estrutura de TI. Esta identificação é feita a partir da análise dos processos de negócios do órgão demandante e dos seus objetivos estratégicos 
expressos nos documentos do planejamento estratégico. Caso seja verificado que o sistema demandado não tem aderência ao negócio do órgão, a solicitação de demanda deverá ser indeferida. Caso a demanda seja classificada como procedimento de controle administrativo, será verificado se a solução já não está contemplada em algum outro órgão da organização. Tal providência tem como objetivo o aproveitamento dos recursos de SI da organização, através da otimização dos recursos existentes. Para alcançar estes objetivos, são realizadas as atividades descritas na Tabela 2.

Tabela 2. Atividades previstas na segunda etapa

\begin{tabular}{|c|c|c|}
\hline Atividade & Descrição & Responsável \\
\hline $\begin{array}{l}\text { Registro do Recebimento da } \\
\text { demanda }\end{array}$ & $\begin{array}{l}\text { É protocolado o recebimento da demanda de SI } \\
\text { pelo órgão gestor de TI. }\end{array}$ & \multirow{5}{*}{ Órgão de TI } \\
\hline $\begin{array}{l}\text { Conhecimento do órgão } \\
\text { demandante e dos objetivos } \\
\text { estratégicos }\end{array}$ & $\begin{array}{l}\text { São pesquisados e analisados os documentos } \\
\text { referentes a missão, objetivos organizacionais, } \\
\text { regimento interno e de atuação do órgão }\end{array}$ & \\
\hline $\begin{array}{l}\text { Verificação da estrutura de } \\
\text { TI }\end{array}$ & $\begin{array}{l}\text { É analisada a infraestrutura de TI disponível para } \\
\text { atendimento ao órgão demandante. }\end{array}$ & \\
\hline Análise da demanda & $\begin{array}{l}\text { É verificada a relação da demanda de SI com os } \\
\text { objetivos estratégicos do órgão demandante. }\end{array}$ & \\
\hline $\begin{array}{l}\text { Avaliação da pertinência da } \\
\text { demanda }\end{array}$ & $\begin{array}{l}\text { A demanda é avaliada sob o aspecto de sua } \\
\text { pertinência. Caso não seja procedente, o } \\
\text { demandante é comunicado e a demanda } \\
\text { arquivada }\end{array}$ & \\
\hline
\end{tabular}

\subsection{Coleta de requisitos básicos ao entendimento do SI}

O objetivo desta etapa é a definição dos requisitos principais das funcionalidades do sistema. Para isto, são realizadas as atividades descritas na Tabela 3.

Tabela 3. Atividades previstas na terceira etapa

\begin{tabular}{|l|l|c|}
\hline \multicolumn{1}{|c|}{ Atividade } & \multicolumn{1}{|c|}{ Descrição } & Responsável \\
\hline Coleta de requisitos & $\begin{array}{l}\text { São coletados os requisitos básicos necessários } \\
\text { ao entendimento do sistema demandado. }\end{array}$ & \\
\cline { 1 - 2 } $\begin{array}{l}\text { Validação e Classificação } \\
\text { de requisitos }\end{array}$ & $\begin{array}{l}\text { Os requisitos são classificados em funcionais e } \\
\text { não-funcionais e atribuída ordem de prioridade. }\end{array}$ & Órgão de TI \\
\cline { 1 - 3 } $\begin{array}{l}\text { Elaboração do Documento } \\
\text { de Requisitos }\end{array}$ & $\begin{array}{l}\text { É elaborado o Documento de Requisitos contendo } \\
\text { os principais requisitos funcionais e não } \\
\text { funcionais. }\end{array}$ & \\
\hline
\end{tabular}

\subsection{Estudo de viabilidade de projeto de SI}

O estudo de viabilidade tem como principal objetivo verificar, ainda na fase do anteprojeto, se o projeto de sistema demandado atende as condições requeridas para seu prosseguimento. A análise de viabilidade tem como entrada o documento de requisitos e é formulada sob quatro aspectos: operacional, técnica, econômica e de cronograma. Para tanto, são realizadas as atividades descritas na Tabela 4.

O estudo de viabilidade operacional tem por objetivo medir o grau de adequação da solução, apresentando subsídios para a tomada de decisão pelo órgão de TI, quanto à continuidade do projeto. Desta forma, são analisadas as seguintes questões relativas ao órgão demandante: (i) apoio da gerência; (ii) mudanças no ambiente de trabalho; (iii) percepção dos usuários do sistema requerido e possíveis resistências, superações e adaptações a nova rotina informatizada. 
O estudo de viabilidade técnica tem a finalidade de verificar se a solução ou a tecnologia proposta tem condições de ser colocada em prática, se é suportada pela infraestrutura disponível e se são acessíveis à tecnologia e o conhecimento técnico necessário. Caso a tecnologia necessária não esteja disponível, deve-se avaliar se ela pode ser adquirida ou se poderá ser desenvolvida.

O estudo da viabilidade de cronograma tem como objetivo avaliar a razoabilidade do cronograma do projeto. Contribuem nesta estimativa, as lições aprendidas e o histórico de projetos.

A análise da viabilidade econômica permite julgar se há recursos disponíveis para custear o projeto e se os possíveis benefícios da solução do problema são ou não vantajosos. Ao final desta etapa, é elaborado o relatório de análise de viabilidade da demanda, com o respectivo parecer técnico.

Tabela 4. Atividades previstas na quarta etapa

\begin{tabular}{|c|c|c|}
\hline Atividade & Descrição & Responsável \\
\hline $\begin{array}{l}\text { Estudo da viabilidade } \\
\text { Operacional }\end{array}$ & $\begin{array}{l}\text { Verifica se projeto dispõe de recursos } \\
\text { operacionais suficientes para resolver o problema. }\end{array}$ & \multirow{5}{*}{ Órgão de TI } \\
\hline $\begin{array}{l}\text { Estudo de viabilidade } \\
\text { técnica }\end{array}$ & $\begin{array}{l}\text { Objetiva verificar se a tecnologia disponível é } \\
\text { suficiente para resolução do problema. }\end{array}$ & \\
\hline $\begin{array}{l}\text { Estudo de viabilidade } \\
\text { Econômica }\end{array}$ & $\begin{array}{l}\text { São verificados os custos do projeto } \\
\text { confrontando-os com os recursos disponíveis e a } \\
\text { sua relação custo-benefício. }\end{array}$ & \\
\hline $\begin{array}{l}\text { Estudo de viabilidade de } \\
\text { cronograma }\end{array}$ & $\begin{array}{l}\text { É realizada uma estimativa do tempo para o } \\
\text { atendimento da demanda para verificar se este é } \\
\text { compatível com a expectativa de prazo solicitada } \\
\text { pelo órgão demandante. }\end{array}$ & \\
\hline $\begin{array}{l}\text { Elaboração do Relatório de } \\
\text { Análise de Viabilidade }\end{array}$ & $\begin{array}{l}\text { É elaborado um relatório com os resultados dos } \\
\text { estudos de viabilidade, no qual será emitido um } \\
\text { parecer. }\end{array}$ & \\
\hline
\end{tabular}

\subsection{Elaboração da proposta de SI}

Esta etapa tem como objetivo dar ciência ao órgão demandante dos estudos e análises realizadas acerca da demanda solicitada e permitir a tomada de decisão do órgão demandante quanto a implementação do projeto de SI, no caso da demanda ser considerada viável pelo órgão de TI. As atividades desta etapa são descritas na Tabela 5. Caso o estudo de viabilidade realizado tenha parecer desfavorável, o órgão demandante é informado e a demanda arquivada. Caso o parecer técnico seja favorável, é elaborada uma proposta de negócio de SI para encaminhamento ao órgão demandante.

Uma vez aprovada a proposta de SI pelos seus gestores, os órgãos envolvidos assumem compromissos em relação aos custos, prazos e condições envolvidas no projeto de SI. O compromisso assumido justifica as decisões administrativas, revestindo-as do princípio da transparência requerida no serviço público. 
Tabela 5. Atividades previstas na quinta etapa

\begin{tabular}{|c|c|c|}
\hline Atividade & Descrição & Responsável \\
\hline $\begin{array}{l}\text { Análise e parecer sobre o } \\
\text { projeto de SI }\end{array}$ & $\begin{array}{l}\text { O comitê gestor do órgão de } \mathrm{TI} \text { analisa } \\
\text { documentos e o parecer técnico da demanda e } \\
\text { delibera sobre a viabilidade do projeto. Caso } \\
\text { viável, encaminha-se para elaboração da } \\
\text { Proposta de SI. Caso contrário, o demandante } \\
\text { será comunicado com as respectivas justificativas. }\end{array}$ & \multirow[t]{3}{*}{ Órgão de TI } \\
\hline $\begin{array}{l}\text { Elaboração da Proposta de } \\
\text { Negócio }\end{array}$ & Será elaborada a Proposta de Negócio de TI. & \\
\hline $\begin{array}{l}\text { Encaminhamento ao órgão } \\
\text { demandante }\end{array}$ & $\begin{array}{l}\text { A Proposta de Negócio de SI é encaminhada ao } \\
\text { órgão demandante para análise. }\end{array}$ & \\
\hline
\end{tabular}

\subsection{Elaboração da documentação legal para processo de aquisição de SI}

Esta etapa tem como objetivo a elaboração de documentação de contratação (termo de referência) para elaboração do SI. O órgão demandante recebe a proposta de negócio de SI do órgão de TI e analisa as condições pela quais sua demanda pode ser atendida. Caso a proposta seja aprovada, é manifestada sua concordância pelo seu gestor e a proposta é devolvida ao órgão de TI para providências.

O termo de referência proposto contém as condições a serem observadas pelo executor do projeto em relação ao objeto especificado no escopo do sistema. O termo de referência deve estar de acordo com as recomendações do Tribunal de Contas da União (TCU,2007), revestindo-se do princípio da legalidade requerido no serviço público. As atividades envolvidas nesta etapa são descritas na Tabela 6.

Tabela 6. Atividades previstas na sexta etapa

\begin{tabular}{|c|c|c|}
\hline Atividade & Descrição & Responsável \\
\hline $\begin{array}{l}\text { Registro do Recebimento da } \\
\text { Proposta de Negócio }\end{array}$ & $\begin{array}{l}\text { O documento encaminhado pelo órgão de TI é } \\
\text { recepcionado e protocolado no órgão } \\
\text { demandante. }\end{array}$ & \multirow{4}{*}{$\begin{array}{l}\text { Órgão } \\
\text { Demandante }\end{array}$} \\
\hline $\begin{array}{l}\text { Análise da proposta de } \\
\text { negócio }\end{array}$ & $\begin{array}{l}\text { O Demandante toma ciência e analisa a proposta } \\
\text { encaminhada pelo órgão de TI. }\end{array}$ & \\
\hline $\begin{array}{l}\text { Tomada de decisão quanto } \\
\text { a implantação do projeto. }\end{array}$ & $\begin{array}{l}\text { O órgão demandante toma a decisão quanto à } \\
\text { implantação do projeto. Em caso desfavorável, o } \\
\text { órgão de TI é comunicado. }\end{array}$ & \\
\hline $\begin{array}{l}\text { Encaminhamento ao órgão } \\
\text { de TI }\end{array}$ & $\begin{array}{l}\text { Caso aprovada, o órgão demandante encaminha } \\
\text { ao órgão de TI a proposta de negócio autorizada. }\end{array}$ & \\
\hline $\begin{array}{l}\text { Registro do recebimento da } \\
\text { proposta aprovada }\end{array}$ & $\begin{array}{l}\text { O documento encaminhado pelo Órgão } \\
\text { Demandante é recepcionado e protocolado no } \\
\text { órgão de TI. }\end{array}$ & \multirow{3}{*}{ Órgão de TI } \\
\hline $\begin{array}{l}\text { Confecção da } \\
\text { documentação legal }\end{array}$ & É elaborado o Termo de Referência & \\
\hline $\begin{array}{l}\text { Encaminhamento ao } \\
\text { responsável pela } \\
\text { contratação. }\end{array}$ & $\begin{array}{l}\text { O documento é encaminhado para o setor } \\
\text { responsável pelo processo de contratação. }\end{array}$ & \\
\hline
\end{tabular}

\section{A aplicação do modelo na Prefeitura Municipal de Salvador}

Este modelo proposto foi implementado na empresa COGEL - Companhia de Governança Eletrônica do Município de Salvador, no estado da Bahia, permitindo assim sua aplicação e avaliação. A COGEL é uma empresa pública municipal que tem por 
finalidade planejar, coordenar, executar e controlar as ações relacionadas à gestão da informação e da telecomunicação na Prefeitura Municipal do Salvador (PMS).

Inicialmente, foi realizada uma "Prova de Conceito" ou PoC (Proof of Concept), proposta por Carsten (1989), que consiste em uma avaliação feita por especialistas com o objetivo de aferir se um modelo opera como o idealizado, no propósito de verificar se o conceito ou teoria é suscetível de ser explorado de maneira útil. Por característica da metodologia de pesquisa adotada, "Pesquisa Ação" (Action Research), os analistas participantes foram os integrantes do quadro técnico da própria empresa. A COGEL possui uma área de Gerencia de Projetos (GP) que conta em seu quadro com seis analistas de sistemas e um analista de processos que possuem prática na utilização de modelos de desenvolvimento de SI da COGEL desde as primeiras versões.

Após as avaliações conceituais do modelo por meio da Prova de Conceito, passou-se para a fase da sua aplicação em demandas de sistemas de Informação na COGEL, oportunidade em que o modelo pode ser avaliado através da execução prática das suas etapas. O mesmo foi submetido à apreciação dos gerentes de projeto da COGEL para colher sugestões e contribuições para o aprimoramento das etapas propostas, sendo realizadas reuniões semanais para discussão em grupo e avaliação do modelo. É relatada a situação anterior ao uso do modelo, a situação após a sua implantação e os benefícios observados:

(i) Formalização das demandas de SI: Antes da aplicação do modelo, as demandas de sistemas de SI não obedeciam a um procedimento formal, permitindo que em muitos casos, o órgão demandante contratasse serviços de desenvolvimento de sistemas diretamente com empresas de TI sem a interveniência da COGEL. Tal procedimento incorria em falta de padronização dos sistemas, deficiências no acompanhamento dos projetos, entrega de software com defeitos, decorrentes da insuficiência técnica do órgão em acompanhar o processo de desenvolvimento de sistemas. Com o direcionamento das demandas para a COGEL, ficou formalizado o compromisso do gestor do órgão em apoiar os estudos da área de TI da COGEL.

(ii) Compreensão do contexto e do domínio da aplicação: Anteriormente à utilização do modelo, era comum encontrar documentos de análise de demandas de SI, sem qualquer análise de sua relação com os objetivos estratégicos do órgão demandante. Atualmente, parte-se da premissa de que o desenvolvimento de sistemas de informação deve estar diretamente relacionado com estes objetivos, expressos através do seu regimento interno e planejamento estratégico.

(iii) Entendimento do SI: A coleta dos requisitos na fase de iniciação do projeto de SI era realizada para projetar um rascunho da arquitetura do sistema, para estimar os seus custos e obter uma estimativa de tempo para o seu desenvolvimento. Esses estudos eram realizados somente após a abertura do projeto e desta forma, custos inerentes à implantação de projetos eram dispendidos. Comumente ocorria interrupção de projetos, ocasionando desperdício de recursos. Atualmente, além destes requisitos, são também identificados os requisitos não funcionais envolvidos, com destaque para os organizacionais e diretamente envolvidos nas áreas de conhecimento do guia PMBOK (PMBOK,2008) para gerenciamento de projetos, os quais ficam evidenciados anteriormente a decisão de implementação dos projetos. Assim, pode-se conhecer as 
nuances da cultura organizacional, as particularidades existentes nos setores em relação à resolução de pendências e dificuldades na aplicação dos sistemas informatizados.

(iv) Análise da viabilidade do sistema demandado: Anteriormente, não eram realizados estudos de viabilidade de sistemas. Eram feitas somente estimativas de custos e de tempo para o projeto de SI, de forma a projetar uma estimativa orçamentária e necessidade de tempo gasto para desenvolvimento. Não havia um estudo de viabilidade sob a ótica técnica, operacional, econômica e de cronograma para verificação da conveniência de se dispender recursos no desenvolvimento de um sistema. Por isso, não era considerada a infraestrutura de TI existente, verificando se a plataforma computacional poderia suportar a aplicação. Esta falta de observação em relação ao parque tecnológico causava problemas como lentidão, inoperância, falha de comunicação de rede com o servidor da aplicação.

(v) Formalização da proposta de negócio de SI: Anteriormente, não era explicitada a fonte de recursos a ser utilizada, o que causava dúvidas em relação ao custeio do sistema. Também não era requerida autorização expressa dos gestores para consecução do projeto no documento. Em razão disso, uma expressiva quantidade de propostas de SI elaborados eram arquivadas sem dar sequência ao projeto, por não conterem elementos suficientes para embasar a decisão de sua aquisição. No atual modelo, a proposta de negócio constitui um documento com referências técnicas, de forma que se tenha a justificativa e o entendimento da proposta através desse documento.

(vi) Elaboração da documentação legal para processo de aquisição ou contratação para desenvolvimento de SI: Os casos envolvendo contratação de SI, os modelos de termos de referência eram omissos em aspectos como ambiente operacional, linguagem de programação. Tais omissões davam margem às empresas vencedoras para codificar o sistema em uma linguagem proprietária ou utilizando framework próprio, implicando na necessidade de contratação de manutenção do SI. Atualmente, verifica-se uma maior facilidade na elaboração do termo de referência, uma vez que várias informações relacionadas ao termo são coletadas na execução das etapas do modelo, suprimindo os problemas que anteriormente ocorriam.

\section{Conclusões}

Este modelo foi elaborado com o intuito de contribuir para a qualidade no desenvolvimento de SI na área pública. Todavia, sua aplicabilidade pode ser estendida a outras organizações que possuem problemas semelhantes.

O modelo de processo apresentado neste trabalho contribuiu para o estabelecimento de procedimentos formais a serem adotados nos casos das demandas de SI. Os gestores passaram a dispor de subsídios para a tomada de decisão quanto à implantação do projeto de SI, verificando sua aderência aos objetivos estratégicos da organização. O ambiente organizacional tornou-se melhor definido evidenciando o cenário envolvido de aplicação do SI Além disto, o modelo contribuiu para a melhoria da qualidade dos documentos legais para subsidiar a aquisição de soluções de software, seja através de compra ou desenvolvimento.

A fim de torná-lo aderente ao ambiente local em que é aplicado, há a necessidade do envolvimento do quadro de TI responsável pelo estudo das demandas de 
TI, para que o modelo proposto seja devidamente adequado, permitindo a implantação, evolução e o constante aperfeiçoamento de suas etapas.

Como trabalhos futuros, elencamos a possibilidade de adaptação do modelo para outras demandas de TI, como na contratação de serviços de rede, serviços de datacenter e de vídeo monitoramento, dentre outros. A elaboração de um sistema informatizado para automatização e gerenciamento do próprio modelo também é desejável.

\section{Referências}

Ameller, D.; Ayala, C. (2012) "Functional requirements in software architecture practice" In: Magazine of Software Engineering for Information Systems Group Universitat Politècnica de Catalunya (GESSI-UPC), Barcelona, Spain - AtlanMod, INRIA - École des Mines de Nantes, Nantes, France, Report ESSI-TR-12-1. Mar., 2012.

Baldam, R. L. et al. (2010) "Gerenciamento de Processos de Negócios BPM - Business Process Management”. Erica: São Paulo, SP.

Banco do Estado do Espírito Santo (Banestes) (2010). MGS - Modelo de Gestão de Sistemas - Edital 004/2010 Processo 8090-0 anexoVI, pp 27 a 84. Disponível em $<$ http://www.portaisgoverno.pe.gov.br/c/document library/get file?uuid=768b0d794386-4758-9e4d-b6be88397a93\&groupId=335215>. Acessado em: 20 jul. 2012.

BRASIL, TCU - Tribunal de Contas da União. (2007). "Manual On-line de Contratação e Jurisprudência de Contratação de Serviços de TI" - Site elaborado pelo TCU Tribunal de Contas da União - Atualizado em 20 dez. 2007. Disponível em: $<$ http://portal2.tcu.gov.br/portal/page/portal/ticontrole/legislacao/repositorio_contrata cao_ti/ManualOnLine.html>. Acessado em: 20 jul. 2012.

BRASIL, Ministério da Educação e Cultura. MGDS - Metodologia de Desenvolvimento de Sistemas MEC/INEP (2010). Edital do Pregão Eletrônico n ${ }^{0}$ 11/2010 DTDIE/INEP, Processo N. ${ }^{\circ}$ 23036.000324/2010, de 10/06/2010 - Brasília (DF), $\begin{array}{lllll}\text { Pagina } & 89 & \text { a } & 382 . & \text { Disponível }\end{array}$ $<$ http://www.portaisgoverno.pe.gov.br/c/document library/get file?uuid=16ec $3 \mathrm{~d} 1 \mathrm{f}-$ d774-4c5d-9930-c76e2486a185\&groupId=335215>. Acessado em: 20 jul. 2012.

BRASIL, Supremo Tribunal Federal (STF). Metodologia de Desenvolvimento de Software (MDS) do STF (2009)- Supremo Tribunal Federal - documento publicado no DOU 03/12/2009, Edital de Pregão Eletrônico no 167/2009. Processo 338.061, anexo $\mathrm{C}$ do Termo de Referência. Disponível em: $<$ www.jusbrasil.com.br/diarios/.../dou-secao-3-03-12-2009-pg-203>. Acesso em 20 jul. 2012.

BRASIL, TRT 11 $1{ }^{\text {a }}$ Região - MDS - Metodologia de Dsenvolvimento de Sistemas Manaus (AM) (2010).Disponível em: <http://governanca.trt11.jus.br/wpcontent/uploads/Doc20100921141640.pdf>. Acessado em 20 jul. 2012.

Catarino I. C. S.; Czarini, E. W. (2008) "Utilizando a Metodologia EKD no Processo de Desenvolvimento de Sistemas de Apoio a Decisão" - Revista UNOPAR Cient. Exatas Tecnol., Londrina, v. 7, p. 77-84, Nov. 2008 
Centro de Tecnologia de Informação e Comunicação do Estado do Rio de Janeiro (PRODERJ) (2010) Método de Desenvolvimento de Sistemas - MDS PRODERJ. Centro de Tecnologia de Informação e Comunicação do Estado do Rio de Janeiro documento publicado pelo PRODERJ no Edital de Pregão Eletrônico 012/2010 Registro de Preços - Apensos $n^{\circ}$ VIII a X. Centro de Tecnologia de Informação e comunicação do Estado do Rio de Janeiro - PRODERJ. $<$ http://arquivos.proderj.rj.gov.br/proderj imagens/Licitacoes/UpLicitacoes/Edital P E RP 012.pdf $>$. Acessado em 20/07/2012.

Chichinelli, M and Cazarini, E. W. (2001) "Modelagem Organizacional: uma ferramenta fundamental para o desenvolvimento dos sistemas de informação na fase de definição de requisitos." In: Simpósio de Engenharia de requisitos, 8, 2001, Bauru, São Paulo.Universidade Estadual Paulista. Disponível em: $<$ http://www.simpep.feb.unesp.br/ana8.html> Acesso em: 08 jan. 2013.

Carsten, B. (1989) “Carsten's Corner” In: Magazine Power Conversion and Intelligent Motion, Nov. 1989, pag. 38.

Kruchten, P. (2003 "Introdução ao RUP - Rational Unified Process", Editora Ciência Moderna Ltda., Rio de Janeiro .

La Costa, L. and Zoucas, A. (2012). "Elicitação de Requisitos de Software no Setor Público",In: Article of IX SEGeT2012 Simpósio de Excelência em Gestão e Tecnologia, 2012.

Marconi, M. and Lakatos, E.(2001) "Metodologia Cientifica: Ciência e Conhecimento Científico.”5. ed.: Atlas, São Paulo, SP.

Moreira, J. R. P.; Silva, P. C .(2013) "IT management model for financial report issuance and regulatory and legal compliance." JISTEM - Journal of Information Systems and Technology Management Revista de Gestão da Tecnologia e Sistemas de Informação Vol. 10, No. 3, Sept/Dec., 2013 pp.597-620 ISSN online: 1807-1775 DOI: $10.4301 / \mathrm{S} 1807-17752013000300008$.

Muniz, C. R. (2006). "EKD na Administração Pública: Um ensaio sobre a aplicação da Metodologia EKD em uma instância da administração pública direta da Cidade de Ribeirão Preto" Artigo pertencente ao relatório Interfaces temáticas e interativas para os serviços urbanos. Relatório Técnico CNPq Proc 350706 /1999-9 - Fev. 2006.

Project Management Institute, PMI.(2008). "Um Guia do Conjunto de Conhecimentos em Gerenciamento de Projetos". Guia PMBOK, 4. ed. Newtown Square: Four Campus Boulevard, EEUU.

Tamaki, P.A.O. "Uma extensão do RUP com ênfase no gerenciamento de projetos do PMBoK baseada em process patterns"( 2007) . Dissertação (Mestrado em Sistemas Digitais) - Escola Politécnica, USP - São Paulo. Acesso em 16 jan. 2013. Disponível em: <http:/www.teses.usp.br/teses/disponiveis/3/3141/tde-08012008-113326/>

SOFTEX, Associação para Promoção da Excelência do Software Brasileiro.(2001). "MPS. BR - Guia de Aquisição", out. 2011. Disponível em: $<$ http://www.softex.br/mpsbr/_guias/guias/MPS.BR_Guia_de_Aquisicao_2011.pdf>. Acessado em: 20 Abril, 2013. 